\title{
La gestión de los puertos de interés general. Actividad comercial y dominio público
}

\author{
Ángel Sánchez Blanco \\ Catedrático de Derecho Administrativo de la Universidad de Málaga
}

Sumario: I. LOS PUERTOS DE INTERÉS GENERAL EN EL MARCO INSTITUCIONAL DE LA COMPETENCIA ECONÓMICA. II. LAS PECULIARIDADES DE LOS PUERTOS DE INTERÉS GENERAL: SU UBICACIÓN EN EL DOMINIO PÚBLICO MARÍTIMO TERRESTRE Y EL CONDICIONAMIENTO DE SUS ACTUACIONES POR LAS PREMISAS CONSTITUCIONALES DEL ARTÍCULO 132 DE LA CONSTITUCIÓN DE 1978 Y POR LOS CONDICIONANTES LEGALES DE LA LEY DE COSTAS DE 1978. III. EL CAMBIO EN LOS USOS PORTUARIOS Y EN EL DISEÑO DE LOS PUERTOS, Y EL INTENTO DE PATRIMONIALIZACIÓN DEL DOMINIO PÚBLICO MARÍTIMO TERRESTRE POR LOS PUERTOS. IV. LA NECESARIA RECONDUCCIÓN DE LOS PUERTOS A LAS EXIGENCIAS CONSTITUCIONALES DEL ARTÍCULO 132 DE LA CONSTITUCIÓN Y A LAS PREVISIONES LEGALES DE LA LEY DE COSTAS DE 1988 Y DE LA PROPIA LEY DE PUERTOS DE 1992-1997.

\section{LOS PUERTOS DE INTERÉS GENERAL EN EL MARCO INSTITUCIONAL DE LA COMPETENCIA ECONÓMICA}

El repliegue de la intervención administrativa, la reducción de las actividades públicas en el ámbito económico, la misión pública de creación de un mercado competitivo y el objetivo público de situar en la mejor posición posible a los agentes económicos en los mercados internacionales, predeterminan la actividad de los poderes públicos.

El bienestar social y el prestigio internacional de los Estados está identificado por los beneficios que obtienen sus empresarios en los intercambios internacionales, sin obviar la atención pública a los contenidos sintetizables en el objetivo de cohesión y su proyección social e institucional en el que también radican los coherentes resultados económicos.

En este marco, en el que la racionalidad del conjunto social está condicionada por la racionalidad económica del sistema empresarial, el repliegue en la intervención pública es paralelo a la revisión de las categorías jurídicas en las que se apoyan las técnicas de gestión administrativa.

Los efectos sobre el aparato público de la nueva metodología institucional son patentes en la reconversión de los patrimonios de los antiguos 
monopolios, en la privatización de los patrimonios públicos afectos a los Ministerios de Defensa y Justicia, en la enajenación de parte significativa de las sedes provinciales del Banco de España.

La incorporación al mercado de importantes patrimonios, hasta ahora vinculados al sector público, ha actuado como un beneficioso factor de dinamización económica, generador de rentas y empleo, y requiere del complemento de una profunda revisión de las estructuras administrativas, orientada por el criterio de revisión institucional de sus funciones y prestaciones, para conseguir el objetivo de reducir las funciones públicas al ámbito en el que se expresa y aprecia su necesidad y su eficacia por no poder ser atendido por el sector privado.

En este marco, de repliegue de las personas, de las formas y procedimientos públicos, se sitúa la Ley de Puertos de 1992 y su reforma de 1997, mediante la configuración de la estructura organizativa de los puertos con un Consejo de Administración, participado y corresponsabilizado por un amplio espectro de representaciones sociales, empresariales y profesionales, que completan la presencia de las Administraciones públicas territoriales y que justifican el otorgamiento a cada puerto, como entidad pública, del calificativo de Autoridad Portuaria, en coherencia con la integración organizativa y operativa de factores administrativos, profesionales, empresariales y laborales que implica la actividad portuaria.

La gestión en régimen de Derecho privado de los puertos coexiste con el referente político administrativo de atribuir el nombramiento de la presidencia de los puertos de interés general al Consejo de Gobierno de la Comunidad Autónoma, medida que, con independencia de su gestación - por directo efecto del pacto de legislatura de 1996-, es coherente interpretar como el mejor modo para adecuar la gestión empresarial de los tráficos comerciales de cada puerto a la problemática social, empresarial, laboral e institucional de cada ámbito territorial.

La gestión en régimen de Derecho privado de los puertos coexiste también con la necesaria aplicación de los procedimientos de concesión administrativa para el uso del dominio público portuario, en calidad de referente jurídico sobre el que se asienta la actividad del puerto.

La armónica coexistencia de formas jurídicas públicas y formas jurídico privadas tiene afortunada ejemplificación en la Ley de Puertos 1992, con sus modificaciones de 1997, y el específico análisis de la estructura organizativa y de las técnicas de gestión de los puertos, es un cualificado punto de referencia para la proyección de sus más positivas experiencias, 
en el objetivo de revisión de las estructuras públicas y de la consecuente labor de delimitar los ámbitos de actuación, en régimen de Derecho privado, y los ámbitos de actuación, en régimen de Derecho público.

\section{LAS PECULIARIDADES DE LOS PUERTOS DE INTERÉS GENERAL: SU UBICACIÓN EN EL DOMINIO PÚBLICO MARÍTIMO TERRESTRE Y EL CONDICIONAMIENTO DE SUS ACTUACIONES POR LAS PREMISAS CONSTITUCIONALES DEL ARTÍCULO 132 DE LA CONSTITUCIÓN DE 1978 Y POR LOS CONDICIONANTES LEGALES DE LA LEY DE COSTAS DE 1978}

Un preciso y contundente sentido alternativo orientó la elaboración del artículo 132 de la Constitución en su regulación de los bienes de dominio público y en su específica atención a los bienes de dominio público marítimo terrestre.

En contraste con las desviaciones que propició la Ley de Costas de 1969, por efecto de una controvertida interpretación jurisdiccional de la Ley de Aguas de 1866 y de la Ley de Puertos de 1880, que alentó la apropiación del dominio público por los particulares instrumentalizando el Registro de la Propiedad ${ }^{1}$, las Cortes constituyentes afirmaron de modo muy explícito, en el innovador precepto constitucional, el carácter demanial de la zona marítimo terrestre, de las playas, el mar territorial y los recursos naturales de la zona económica y la plataforma continental ${ }^{2}$.

La relación nominativa de bienes transcrita que realiza el artículo 132 de la Constitución agrega el significativo dato de precisar su naturaleza

\footnotetext{
${ }^{1}$ La síntesis de esta problemática está en el trabajo de Nemesio Rodríguez Moro: «Comentario a la Sentencia del Tribunal Supremo de 19 de junio de 1967, AZ 3171, que resuelve el caso de los enclaves privados en la zona marítimo terrestre de las islas Sálvora, Vienta y Nora, situadas en la desembocadura de la Ría de Arosa», Revista de Estudios de la Vida Local nº 157 (1968), pp. 133155, y en la recensión de este trabajo por Lorenzo MARTíN-RETORTILlo BAQUER: La propiedad privada en la zona marítimo terrestre, en Revista de Administración Pública $\mathrm{n}^{\circ} .56$ (1968) y en su libro El «Vía Crucis» de las libertades públicas y otros ensayos rescatados, Ediciones Ciudad Argentina, Buenos Aires 1996, pp. 231-242.

${ }^{2}$ Remito a los precisos datos del proceso de elaboración de este precepto, aportados por el Senador constituyente, y anterior analista académico de la problemática jurídica que afectó a las costas en el marco de la Ley de 1969, Lorenzo Martín-Retortillo Baquer: Materiales para una Constitución (Los trabajos de un profesor en la Comisión Constitucional del Senado), Editorial Akal, Madrid 1984, pp. 225-343.
} 
jurídica. Son bienes condicionados, en su uso y gestión, por los principios de inalienabilidad, imprescriptibilidad e inembargabilidad que definen el régimen constitucional de los bienes de dominio público con la firme voluntad institucional de sustraerlos a destinos que los puedan hacer objeto de transacción por personas físicas o jurídicas privadas.

La Ley de Costas de 1988 cumple el mandato constitucional de regular por ley estos bienes en directo cumplimiento de la previsión del mismo artículo 132, y en directo cumplimiento de la previsión del artículo 45 del mismo texto constitucional, al mandatar al conjunto institucional de los Poderes Públicos para velar por la utilización racional de los recursos naturales, con el objetivo institucional de proteger y mejorar la calidad de vida y defender y restaurar el medio ambiente, apoyándose en la indispensable solidaridad colectiva.

La Ley de Aguas de 1985 se inscribe en la misma alternativa institucional, precisa las superficies afectas al dominio público hidráulico, y la relativización de algunos de sus criterios por la reforma de 1999, han sido neutralizados por la Directiva del Parlamento Europeo y del Consejo 2000/60, de 23 de octubre, sobre el Marco Comunitario en Política de Aguas, que incorpora a la metodología institucional de la Unión Europea la metodología española de los Planes Hidrológicos.

La aprobación de la Recomendación del Parlamento Europeo y del Consejo de 30 de mayo de 2002 sobre la aplicación de la gestión integrada de las zonas costeras de Europa (DOCE L 148/24, 6.6.2002) y la Decisión del Parlamento Europeo y del Consejo de 22 de julio de 2002, por la que se establece el Sexto Programa de Acción Comunitario en Materia de Medio Ambiente (Decisión no. 1600/2002, DOCE L 242/1, 10-9-2002), ratifican los contenidos de la Ley de Costas española de 1978 y permiten apreciar, en similitud con la incidencia de la Ley de Aguas española sobre la Directiva Marco de Aguas, la incidencia de la Ley de Costas española en la armonización de una política de gestión integrada de las zonas costeras del conjunto de Europa y, muy en particular, de las costas mediterráneas.

El énfasis constitucional en el dominio público marítimo terrestre, desde su consideración de recurso natural predeterminado por el imperativo de su utilización racional, justifica la interrelación — histórica ${ }^{3}$ y actual— de la Ley de Costas de 1988 y de la Ley de Puertos de 1992, mediante la articu-

\footnotetext{
${ }^{3}$ En clave histórica, la interconexión de los referidos textos de la Ley de Aguas de 3 de agosto de 1866 y la Ley de Puertos de 7 de mayo de 1880 y el Decreto-Ley de 19 de enero de 1928.
} 
lación de la Ley de Puertos sobre los preconceptos de la Ley de Costas, y el común factor unitivo de ambas: el dominio público marítimo terrestre se erige en el factor que no puede relativizar ninguna actividad económica fuera de las estrictas previsiones de ambos textos legales.

Particularmente significativa es, dentro de la metodología de interdependencia costas-puertos y puertos-costas, la precisa descripción de lo que es un puerto marítimo, que realiza el artículo 2.1 de la Ley de Puertos:

«A los efectos de esta Ley, se denomina puerto marítimo al conjunto de espacios terrestres, aguas marítimas e instalaciones que, situado en la ribera de la mar o de las rías, reúna condiciones físicas, naturales o artificiales y de organización que permitan la realización de operaciones de tráfico portuario, y sea autorizado para el desarrollo de estas actividades por la Administración competente».

La creatividad empresarial y la capacidad de gestación y materialización de ideas y medios al servicio de la comunidad tiene el límite de los recursos naturales que materializan el dominio público marítimo y, en su caso, el dominio público hidráulico. Ambos tipos de bienes están fuera de posibles transacciones económicas que pretendan tomarlos por objeto y, por ello, el texto constitucional condiciona su régimen jurídico con los principios de inalienabilidad, imprescriptibilidad e inembargabilidad. Connotaciones conceptuales que son tributarias de lo que, con sencillos términos, las Partidas calificaron como res communes omnium y que, con meridiana sencillez, la Ley de Costas pone al servicio del uso público de todos los ciudadanos, delimitando su superficie y garantizando el acceso público al dominio público marítimo terrestre.

Como la realidad ha demostrado, en lo que ha sido la aplicación de la Ley de Costas, no hay condicionantes negativos para la actividad empresarial proveniente de la sustracción al mercado de los bienes del dominio público marítimo terrestre. Al contrario, el sector empresarial privado ha incrementado sustancialmente sus rendimientos como consecuencia de una perfecta delimitación entre lo público y lo privado en las costas españolas, y la inversión pública de la Administración General del Estado, en regeneración de playas y en la construcción de paseos marítimos, en colaboración con Comunidades Autónomas y Ayuntamientos, está en la causa, entre otras, de la determinante posición de España en el sector turístico mundial y la sensible mejora de la calidad urbana de las zonas costeras.

En el marco expuesto, la Ley de Puertos articula sus categorías conceptuales sobre los previos conceptos de la Ley de Costas, de tal modo que, sobre el preexistente concepto de «dominio público marítimo terrestre» de la Ley de Costas, se acuña el concepto de «dominio público por- 
tuario», que implica la recalificación del «dominio público marítimo terrestre», sustrayéndolo de su uso público para adscribirlo al específico uso portuario y darle el calificativo de «dominio público portuario». En esta línea, es muy preciso el artículo 14.2 de la Ley de Puertos:

«Se considera dominio público portuario estatal el dominio público marítimoterrestre afecto a los puertos e instalaciones portuarias de titularidad estatal.»

Para realizar la transformación del «dominio público marítimo terrestre» en «dominio público portuario», conforme al concepto acuñado por el artículo 14.1 de la Ley de Puertos, la propia Ley dispone un pormenorizado procedimiento que, acoge los términos de los artículos 29 y 129 de la vieja Ley de Procedimiento Administrativo de 1958, y trata de conseguir los beneficiosos efectos acumulados de la legalidad, el acierto, la oportunidad, la economía, la celeridad y la eficacia.

El procedimiento previsto por la Ley de Puertos para transformar el dominio público marítimo terrestre en dominio público portuario detalla los organismos intervinientes e informantes y, con precisión en la sucesión temporal de los tramites, integra la técnica de positivización de efectos por el transcurso del plazo para resolver, que propicia la Ley 30/1992, de Régimen Jurídico de la Administraciones Públicas, y concluye con la atribución, al hoy Ministerio de Fomento, de la resolución del expediente, vinculando la calificación del «dominio público portuario» a la «zona de servicio del puerto» correspondiente.

Explícito es el artículo 15 de la Ley:

«1. El Ministerio de Obras Públicas y Transportes (Ministerio de Fomento) delimitará en los puertos de competencia estatal una zona de servicio que incluirá las superficies de tierra y de agua necesarias para la ejecución de sus actividades, las destinadas a tareas complementarias de aquéllas y los espacios de reserva que garanticen la posibilidad de desarrollo de la actividad portuaria.

2. La delimitación de la zona de servicio se hará, a propuesta de la autoridad portuaria, a través de un plan de utilización de los espacios portuarios que incluirá los usos previstos para las diferentes zonas del puerto, así como la justificación de la necesidad o conveniencia de dichos usos.

La aprobación del plan de utilización de los espacios portuarios corresponderá al Ministro de Obras Públicas y Transportes (Ministro de Fomento), previo informe de Puertos del Estado, de la Dirección General de Costas y de las administraciones urbanísticas sobre los aspectos de su competencia, que deberán emitirse en el plazo de un mes, desde la recepción de la propuesta, entendiéndose en sentido favorable si transcurriera dicho plazo sin que el informe se haya emitido de forma expresa. Esta aprobación llevará implícita la declaración de utilidad pública a efectos expropiatorios de los bienes de propiedad privada, así como la afectación al uso 
portuario de los bienes de dominio público incluidos en la zona de servicio que sean de interés para el puerto.»

Obsérvese que la resolución del procedimiento de recalificación como «dominio público portuario» de lo que, conforme a la Ley de Costas es, en origen, calificado y delimitado como «dominio público marítimo terrestre», es sustraída al Consejo de Administración del Puerto y a su Presidente, y es otorgada al Ministerio de Fomento. La justificación es obvia: la «indispensable solidaridad colectiva», que para el uso de los recursos naturales demanda el referido artículo 45 de la Constitución, requiere sustraer a la simple perspectiva de la rentabilidad económica privada lo que, por mandato constitucional, está sustraído al comercio por estar — parafraseando al Rey Sabio - al servicio del uso de todos los hombres.

El expediente a resolver por el Ministerio de Fomento integra la pluralidad de perspectivas que debe avalar, de modo fehaciente, que la sustracción al uso público del «dominio público marítimo terrestre» para afectarlo al «dominio público portuario»y al efectivo cumplimiento de las actividades comerciales de tráfico marítimo del puerto, compensa el detrimento ambiental, y las privaciones en el uso público de los bienes demaniales marítimo terrestres, que los ciudadanos van a sufrir, para poder hacer viable que el puerto utilice la lámina de agua, las playas y los paseos, sustraídos al uso, utilización y disfrute público.

La sustracción de parte de su dominio público que se impone al conjunto de la colectividad social justifica que el puerto, para adscribir dominio público marítimo terrestre a sus usos portuarios, tenga que ser objeto de un procedimiento más complejo que el que afecta al otorgamiento de cualquier otra concesión en el dominio público portuario.

El expediente de delimitación de la zona del servicio del puerto, a efectos de delimitar el dominio público portuario, es el de una concesión especialmente cualificada, como directa consecuencia de los niveles de intensidad en el uso privativo que incorpora y en los efectos que agrega, en detrimento de los valores ambientales, al sustituir los contenidos del recurso natural inicial por las transformaciones que requiere la prestación de los servicios comerciales que definen la actividad portuaria.

La Ley de Costas agrega otro importante dato: elimina cualquier equívoco sobre las transformaciones que pueda padecer el dominio público marítimo terrestre y vincula, de modo explícito, a la categoría de «dominio público», todas las obras que se realicen sobre terrenos ganados al mar, manteniendo la intangibilidad del bien originario objeto de la concesión al 
puerto y, por ello y para ello, lo recalifica como «dominio público portuario». Rotundo es el tenor literal del 4.2 de la Ley de Costas:

«Pertenecen asimismo al dominio público marítimo-terrestre estatal: ...2. Los terrenos ganados al mar como consecuencia directa o indirecta de obras, y los desecados en su ribera».

Los puertos son concesionarios del dominio público marítimo terrestre y están supeditados a las estrictas cláusulas concesionales que determina la propia Ley de Puertos, mediante la exigencia de materializar el Plan de Usos Portuarios, que delimita la Zona de Servicios Portuarios y que recalifica el dominio público marítimo terrestre en dominio público portuario, con sustitución del uso público del dominio público marítimo terrestre y su afección al uso privativo de los servicios portuarios.

La sustracción al uso público está justificada en la prestación por el puerto de los servicios comerciales, conforme a las previsiones del artículo 3 de la Ley, servicios comerciales del puerto de evidente interés público y determinantes de su estructura organizativa y operativa, pero en los que no es relevante la categoría jurídica de servicio público como determinante de la afección demanial.

No hay correlación del dominio público portuario con el concepto de servicio público como determinante de la calificación de dominio público, ya que la actividad portuaria no implica una prestación de servicios al conjunto de la colectividad determinante de un régimen exorbitante y excluyente, como lo pueden realizar las Administraciones territoriales, mediante la afección de sus bienes inmuebles al dominio público por efecto de la radicación en ellos de sus actividades prestacionales.

En el caso de los puertos, cada puerto es competitivo con los otros puertos en un régimen de gestión de Derecho privado de los tráficos marítimos que pueda captar en el mercado y, en cuya actividad, el único referente vinculado al ejercicio de funciones públicas está materializado en la consideración del puerto como área aduanera, lo que requiere incorporar al puerto el vallado de seguridad que delimite el espacio aduanero, cuyo control es ajeno al puerto y es desempeñado por los cuerpos funcionariales de Hacienda con el auxilio de las Fuerzas de Seguridad del Estado.

Conforme a los datos que anteceden, lo puertos marítimos se asientan sobre la preexistente realidad jurídica del dominio público marítimo terrestre, cuyo régimen general de uso público puede ser excepcionado por el régimen concesional general previsto por la Ley de Costas o por el régimen configurado por la Ley de Puertos y, por ello, no son más que unos 
concesionarios afectos a un servicio de interés general, prestado en competencia y en régimen de Derecho privado, y la afección a los usos portuarios del dominio público marítimo terrestre se incardina en el ámbito funcional de las obras que requiere la funcionalidad del tráfico marítimo y la peculiar condición de frontera de los puertos.

El calificativo de Autoridad Portuaria que se personifica en el Consejo de Administración y en su Presidente, conforme a la dicción de los artículos 39 ,a) y 40 de la Ley, no pasa de ser una respuesta terminológica predeterminada por las peculiaridades de los tránsitos mercantiles marítimos, sin que sea posible extraer de ella más afecciones que las relativas a las relaciones jurídicas especiales generadas por las prestaciones de servicios y referenciado en los componentes subjetivos y situaciones especificadas por la propia Ley, en el artículo 3.3, a): marina mercante, transporte marítimo, flota civil española, empresas navieras, régimen de navegación (interior, de costa, exterior y extranacional), aguas en las que España ejerce soberanía, derechos soberanos o jurisdicción.

El efectivo desarrollo de las «competencias de explotación portuaria» es el objetivo que expresa el artículo 18 de la Ley de Puertos, como síntesis de los objetivos que marcan la actividad de un puerto de interés general y, a estos efectos, la Ley, al regular la «Planificación, proyectos y construcción de los puertos» ${ }^{4}$, supedita, a la figura de «Plan especial o instrumento urbanístico equivalente», «la consideración urbanística del puerto», en correlación con la calificación del puerto como «sistema general portuario», y el mismo precepto dispone, en su punto b), que «Su tramitación y aprobación se realizará de acuerdo con lo previsto en la legislación urbanística y de ordenación del territorio, por la Administración competente en materia de urbanismo».

\section{EL CAMBIO EN LOS USOS PORTUARIOS Y EN EL DISEÑO DE LOS PUERTOS, Y EL INTENTO DE PATRIMONIALIZACION DEL DOMINIO PÚBLICO MARÍTIMO TERRESTRE POR LOS PUERTOS}

Los muelles lineales, de escasa profundidad y lindantes con la trama urbana de las ciudades, que permitían la carga y descarga de mercancía sobre el propio muelle por medios convencionales, han sido desvitalizados

\footnotetext{
${ }^{4}$ Sección 3. ${ }^{a}$ del Capítulo I, «Organización, planificación y gestión de los puertos del Estado», Título I, «Organización portuaria del Estado».
} 
por los requerimiento impuestos por la técnica de contenedores, que demanda superficies cuadrangulares para facilitar la logística de los medios de transporte que, a su vez, demandan conexiones rápidas con las distintas infraestructuras de comunicaciones y resolver los problemas de las grandes infraestructuras de transporte en su colindancia urbana.

El resultado del cambio en el modelo portuario se ha traducido en la reubicación de los puertos, cuyas nuevas instalaciones debieran haber propiciado la simple desafectación del dominio público portuario de los muelles en desuso y su reintegro al dominio público marítimo terrestre, conforme a las previsiones de la Ley de Puertos y de la Ley de Costas: desafectación de los muelles innecesarios de la zona del servicio del puerto, con la consecuente segregación del dominio público portuario y, en secuencia, inmediato trazado de las líneas de deslinde del dominio público y de las líneas de servidumbres que prevé la Ley de Costas y, si hubiere superficies que exceden de las líneas de deslinde, la aplicación de las previsiones de la Ley de Costas relativas a servidumbres o, en su caso, de la legislación complementaria de las Comunidades Autónomas que pudiera incrementar las superficies de servidumbre.

El artículo 49.4 de la Ley de Puertos, en redacción de la Ley de reforma de 1997, es particularmente preciso en su enunciado al regular la desafectación de las superficies portuarias innecesarias:

«Los bienes de dominio público portuario que resulten innecesarios para el cumplimiento de fines de este carácter podrán ser desafectados por el Ministro de Fomento, con informe de la Dirección General de Costas a efectos de la protección y defensa del dominio público marítimo-terrestre, previa declaración de innecesariedad por el Consejo de Administración de la Autoridad Portuaria y se incorporarán al patrimonio de ésta, quien podrá proceder a su enajenación o permuta. Si el valor fuera superior a 500.000.000 de pesetas y no excediera de 3.000.000.000 de pesetas, su enajenación deberá, además, ser autorizada por Puertos del Estado, y por el Gobierno cuando sobrepase esta última cantidad.

La Orden del Ministerio de Fomento que acuerde la desafectación conllevará, en su caso, la rectificación de la delimitación de la zona de servicio del puerto contenida en el plan de utilización de los espacios portuarios, y se comunicará al Ministerio de Medio Ambiente a fin de que proceda a la rectificación del deslinde del dominio público marítimo-terrestre existente.

En el caso de que los bienes desafectados conserven sus características naturales de bienes de dominio público marítimo-terrestre, definidos en el artículo 3 de la Ley 22/1988, de 28 de julio, de Costas, tales como playas o zonas de depósito de materiales sueltos, se incorporarán automáticamente al uso propio del dominio público marítimo-terrestre regulado por dicha Ley».

La regulación que realiza del procedimiento de desafectación de la zona de servicio del puerto, como consecuencia de la no necesidad de los bie- 
nes para el servicio portuario, aunque no utiliza términos imperativos, requiere observar que su aplicación incorpora carácter preceptivo: la desafectación como directa consecuencia de lo que no tiene específico uso portuario no puede y no debe estar incorporado a la zona de servicio del puerto $\mathrm{y}$, en consecuencia, no puede ser definido como dominio público portuario y, por ello, no debe ser sustraído al uso público, si se trata de preexistente dominio público marítimo terrestre, o no debe ser sustraído a la rentabilidad económica del puerto, si se trata de superficies o bienes cuya titularidad corresponde al puerto y que deben ser oportunamente rentabilizadas.

El mismo precepto delimita estas dos situaciones, con nitidez: en primer lugar establece que «se incorporarán automáticamente al uso propio del dominio público marítimo terrestre» los bienes naturales del dominio público marítimo terrestre - objeto de la atención del artículo $3-$ y precisa, en un segundo momento, que los bienes del artículo $4 \mathrm{y}$, en particular, «los terrenos ganados al mar como consecuencia directa o indirecta de obras, y los desecados en su ribera»-incluidos en el punto 2 de este mismo artículo en el dominio público marítimo terrestre- tendrán la incorporación diferida.

No obstante, esta inicial dicotomía, en la que subyace la tradicional distinción entre el dominio público natural y el dominio público artificial, y la previsión diferida de incorporación diferida al dominio público de los bienes no naturales, se limita a constatar lo obvio: que el muelle abandonado en sus usos portuarios por los nuevos muelles, cuya construcción fue resultado inexcusable de una obra que ganó terrenos al mar para conseguir el adecuado calado para su uso portuario por la naves en su actividad de carga y descarga, tiene que ser reintegrado — con las superficies adyacentes que dispone la Ley de Costas - al libre uso ciudadano, como parte inescindible del dominio público marítimo terrestre y que, a estos efectos, el cantil define el punto de arranque de las mediciones que han de delimitar el dominio público marítimo terrestre y las superficies con servidumbre.

La referida dicotomía entre bienes del dominio público natural y los bienes del dominio público artificial, como parte de la dualidad en el momento de incorporación al dominio público, se difumina, hasta desaparecer, si se considera que las nuevas playas, producto de obras de ingeniería, no sólo de rehabilitación de playas, sino de creación de playas junto a lo que hasta el momento fueron unos bien batidos pedregales o acantilados, pueden ser consideradas también como parte del dominio público artificial, al ser su arenal producto de una obra pública, sin poder conec- 
tarse su existencia a ningún periodo geológico y poder datar su construcción en el decenio posterior a la vigencia de la Ley de Costas de 1988.

La relativización de la referida dualidad en los tiempos de incorporación no permite ignorar la secuencia que marca las actuaciones administrativas posteriores a la desafectación de muelles, que demanda sucesivas actuaciones:

En primer lugar, la delimitación en los muelles desafectados, en aplicación del procedimiento de deslinde, de la superficie que corresponde al dominio público marítimo terrestre, a efectos de definir la superficie de uso publico y, por ello, nunca patrimonializable en coherencia con las premisas constitucionales de extracomercialidad del dominio público marítimo terrestre.

En segundo término y, a partir de la línea de deslinde, los puertos podrán ver delimitadas, en el resto de la superficie no demanial que se pueda proyectar con referencia en los muelles desafectados, las servidumbres previstas por la Ley de Costas.

Como colofón, los puertos podrán llegar a particularizar las superficies sobre las cuales pueden llegar a ser titulares, con un contenido, en sus posibles usos, que corresponde definir a los instrumentos de programación urbanística, con la incorporación del correlativo valor añadido en el patrimonio del correspondiente puerto y su eventual enajenación.

En contraste con la metodología especificada, requerida por la Ley de Puertos y la Ley de Costas, y que coincide con el procedimiento aplicable en el fin o rescate de cualquier concesión demanial (que demanda las actuaciones administrativas de reintegro al dominio público de lo que temporalmente fue sustraído al uso público, como consecuencia del otorgamiento concesional de un uso privativo), los puertos han abierto la línea de considerar los muelles e instalaciones, sin uso, como uno de sus activos patrimoniales que, incluso, pudiera ser objeto de concesión otorgada por la propia autoridad portuaria.

La alternativa no puede ser considerada más que como un lamentable exceso, perturbador de la propia idea del necesario reintegro al sector privado de áreas de actividad y patrimonios ubicados disfuncionalmente en el ámbito público. Oportuno es afirmar que la misma alternativa, con igual falta de fundamento que los puertos, podrían y quizá deberían intentar el conjunto de concesionarios del dominio público y, no sólo del marítimo terrestre. 
El principio de igualdad pudiera justificar que cualquier concesionario privado de bienes de dominio público marítimo terrestre pueda seguir la línea de despegue de unas Autoridades portuarias que, sin reparar en el régimen privado de las actividades que tienen que gestionar, parecen querer asumir prerrogativas, tan exorbitantes, como es la apropiación, en su beneficio privado, de lo que sólo están habilitadas a utilizar en directa función de la utilidad social de los tránsitos comerciales portuarios.

La exorbitancia de la alternativa, que alcanza el grado máximo de extralimitación, cuando el puerto pretende conceder lo que le fue concedido, a personas físicas o jurídicas para el desarrollo de actividades ajenas al tránsito comercial de mercancías por el puerto, requiere reparar, primero, en la atipicidad de la cesión de concesión para fin distinto y, como consecuencia de ello, en la cautela que incorpora la propia Ley de Puertos, que sólo de modo ocasional y excepcional autoriza actividades que se aparten del fin a desarrollar por los puertos: las actividades vinculadas al tránsito comercial de mercancías.

El artículo 55, en su apartado 2, de la Ley de Puertos, bajo el expresivo título de «Actividades, instalaciones y construcciones permitidas» es particularmente claro y rotundo, como significativa muestra de la exclusión de actividades en los puertos que no estén directamente vinculadas a las «competencias de explotación portuaria», que sintetiza el referido artículo 18 de la Ley de Puertos, como finalidad organizativa y operativa de los puertos:

«Excepcionalmente, y por razones de utilidad pública debidamente acreditadas, el Consejo de Ministros podrá autorizar instalaciones hoteleras en aquellos espacios de los puertos de interés general que estén destinados a las actividades complementarias a que se refiere el apartado 6 de artículo 3, siempre y cuando tales usos hoteleros se acomoden al plan especial o instrumento equivalente referido en el artículo 18. En ningún caso las Autoridades Portuarias podrán participar directa o indirectamente en la explotación o gestión de las instalaciones hoteleras de conformidad con lo previsto en el artículo 37.1.q)».

Por el contrario, en la normal línea de desarrollo de las actividades portuarias está la previsión del artículo 15 , en su punto 6:

«Dentro de la zona de servicio de los puertos comerciales podrán realizarse, además de las actividades comerciales portuarias, las que correspondan a Empresas industriales o comerciales cuya localización en el puerto esté justificada por su relación con el tráfico portuario, por el volumen de los tráficos marítimos que generan, o por los servicios que prestan a los usuarios del puerto, de conformidad con las determinaciones de la ordenación del espacio portuario y del planeamiento urbanístico aplicable.» 
La voluntad legal de distanciamiento de los puertos de actividades no vinculadas a su actividad de tránsito comercial de mercancías que expresa, con particular claridad la remisión, al nivel de Consejo de Ministros, de los expedientes de construcción de hoteles en los puertos, aun reconociendo su carácter complementario para la actividad portuaria, requiere reparar en que el precepto transcrito registra la expresa prohibición de que, en ningún caso, las Autoridades Portuarias podrán participar directa o indirectamente en la explotación o gestión de las instalaciones hoteleras.

Esta precisa previsión de la Ley pretende evitar la «distracción» de las Autoridades Portuarias, tanto del Presidente como del Consejo de Administración, en cualquier actividad que no tenga conexión con su específica responsabilidad pública de prestar el adecuado servicio a los tránsitos marítimos comerciales y lograr, a ser posible, incrementarlos, en beneficio de los resultados económicos del puerto y del entorno social y económico en el que radica, dada la condición de todo puerto de ser un cualificado motor de desarrollo socioeconómico y, como tal, una infraestructura privilegiada que sólo es patrimonio de muy determinadas localidades.

La considerada previsión de prohibir el interesamiento del puerto en las actividades hoteleras, conexas con facilidad a los puertos, es la clave para interpretar las limitadas posibilidades de expansión en los recintos portuarios de las actividades no directamente afectas a la función portuaria de los tránsitos marítimos. $\mathrm{Al}$ respecto, el artículo 3, en su punto 6 dispone:

«Los puertos comerciales que dependan de la Administración del Estado integrarán en la unidad de su gestión los espacios y dársenas pesqueras, así como los espacios destinados a usos náutico-deportivos situados dentro de su zona de servicio. Asimismo podrán incluir en su ámbito espacios destinados a otras actividades no comerciales cuando éstas tengan carácter complementario de la actividad esencial, o a equipamientos culturales o recreativos, certámenes feriales y exposiciones, siempre que no se perjudique globalmente el desarrollo de las operaciones de tráfico portuario.»

La inclusión en el ámbito portuario, con efectos inducidos sobre la funcionalidad de la zona de servicio del puerto, que delimita el dominio portuario, no puede desnaturalizar la actividad del puerto comercial, y la cautela de «que no se perjudique globalmente el desarrollo de las operaciones portuarias» marca la autorización de equipamientos culturales o recreativos, certámenes feriales y exposiciones, que pueden ser episódicos referentes a ubicar en la superficie portuaria, dentro de la dinámica de coherentes relaciones institucionales, administrativas o sociales. 
La firme voluntad de la Ley de que las Autoridades Portuarias no se dispersen en cosas ajenas a la estricta y trascendente actividad comercial del puerto tiene el complemento de las previsiones del transcrito artículo 55.2, al remitirse al artículo 37.1,q) de la propia Ley de Puertos, precepto que, al precisar las competencias del Consejo de Administración del Puerto, le habilita para «Autorizar la participación de la entidad en sociedades mercantiles, y la adquisición o enajenación de sus acciones, cuando el importe de los compromisos contraídos no supere un 5 por 100 de sus ingresos anuales y estas operaciones no impliquen la adquisición o pérdida de la posición mayoritaria», con la precisión de que «el acuerdo del Consejo de Administración deberá contar con el voto favorable de los representantes de la Administración General del Estado» y, al mismo tiempo, condicionar la validez del acuerdo a una irrelativizable exigencia:

«El objeto social de las sociedades mercantiles participadas por la Autoridad Portuaria debe estar ligado al desarrollo de actividades vinculadas a la explotación portuaria».

Conforme a los preceptos que anteceden, la desviación de los puertos, instrumentalizando el dominio público marítimo terrestre, mediante la participación en sociedades, que no tienen por objeto «la explotación portuaria», o pretendiendo retener, en su ámbito patrimonial, bienes de dominio público marítimo terrestre, de facto, y a pesar de estar desafectado de los usos portuarios, para destinarlos a actividades que no tienen relación con «la explotación portuaria», no admite posibles excusas en su manifiesto contraste con los transcritos preceptos de la Ley de Puertos.

Las desviaciones expresadas tampoco pueden pretender encontrar precedente en la práctica de patrimonialización de activos que desarrollan, con particular empeño, empresas privatizadas, como es el caso de RENFE, Tabacalera, o Telefónica, que, a diferencia de los puertos de interés general del Estado, carecen de las expresas limitaciones legales que les impone la propia Ley de Puertos.

Tampoco pueden tener cobertura en las prácticas del Ministerio de Defensa y del Ministerio de Justicia, por las que retienen patrimonios municipales donados en su día por las correspondientes Corporaciones locales para instalaciones militares o prestación de servicios judiciales y que han dejado de utilizarse o prestarse en las superficies o inmuebles donados. Estas prácticas ignoran el condicionante finalista de las previsiones del Código Civil en materia de donaciones y también están en conflicto con irrenunciables premisas jurídicas, como la carencia de titularidades ministeriales, por efecto de la personalidad jurídica única de la 
Administración General del Estado, y la afección funcional de usos a los Departamentos ministeriales, gestionada y racionalizada por la también, de facto, devaluada función del Ministerio de Hacienda, desde la Dirección General de Patrimonio. Estas desviadas prácticas ya incorporan el afortunado y relevante dato jurídico de su descalificación por los Tribunales de Justicia 5 .

El condicionamiento a los Ayuntamientos es parte de la técnica utilizada por la voluntad de patrimonialización del dominio público marítimo terrestre por algunas Autoridades Portuarias: operando con la doble dependencia funcional de la Comunidad Autónoma y de la Administración General del Estado, pretenden hacer ver las dificultades de la aprobación de los planes especiales necesarios, si no hay un acuerdo ventajoso para ambos, y los Ayuntamientos parece que no tienen inconveniente en malograr las expectativas de racionalización de las áreas centrales urbanas mediante la incorporación del frente marítimo, libre del utillaje portuario, por falsas expectativas que implican menoscabo para el uso público de la costa, y no tienen reparo en sustituir el utillaje de los puertos - que puede incluso incorporar el interés cultural de la arquitectura y de la ingeniería del siglo XIX- por actividades que, por estar caracterizadas por el uso masivo e intensivo, están en las antípodas de las previsiones de la Ley de Costas de 1988 y, con frecuencia, en clara oposición a los valores históricos, culturales y cívicos de los centros urbanos en los que se ubican los viejos muelles.

Es el retorno de los puertos, con la inasimilable colaboración de los Ayuntamientos — que no ha excluido la incoherente anuencia de los responsables ambientales autonómicos y centrales-a la privatización de las costas, y a la colmatación urbanística del dominio público marítimo terrestre. Paradójico resultado que supone la inaplicación por los puertos de las precisas previsiones de la Ley de Costas y de la Ley de Puertos en el proceso de desafectación, por desuso, de los viejos muelles, haciendo fracasar la racionalidad que debieran incorporar las calificadas como operaciones puerto-ciudad, que requieren de los oportunos correctivos jurídicos.

\footnotetext{
${ }^{5}$ Sentencia del Tribunal Supremo de 28 de abril de 1993, Magistrado Ponente Sr. Sánchez-Andrade y Sal, Rep. Az. 2777 y Sentencia de 12 de junio de 2001, Magistrado Ponente Sr. Lecumberri Martín, Rep. Az. 7760, ambas relativas a la devolución de las instalaciones militares abandonadas al Ayuntamiento de Lugo y objeto de mi comentario en esta Revista: «Los condicionantes operativos de los patrimonios municipales: de la patrimonialización de las donaciones municipales a los condicionantes normativos del Patrimonio Municipal del Suelo», nº. 288 (2002), pp. 154-162.
} 


\section{LA NECESARIA RECONDUCCIÓN DE LOS PUERTOS A LAS EXIGENCIAS CONSTITUCIONALES DEL ARTÍCULO 132 DE LA CONSTITUCIÓN Y A LAS PREVISIONES LEGALES DE LA LEY DE COSTAS DE 1988 Y DE LA PROPIA LEY DE PUERTOS DE 1992-1997}

La interconexión del dominio público marítimo terrestre y el dominio público portuario para la creación de puertos y la interconexión dominio público portuario y dominio público marítimo terrestre para la desafectación de los usos portuarios, es una coherente y satisfactoria construcción legal que no debe ser relativizada en sus premisas legales y, menos aún, por prácticas en contra de Ley, salvo que se quiera retornar a la noche de los tiempos de las apropiaciones privadas de las costas, que conjuró el artículo 132 de la Constitución y desarrolló la Ley de Costas de 1988 y la Ley de Puertos de 1992.

Coherente es la Resolución de la Secretaría de Estado de Infraestructuras del Ministerio de Fomento, por la que se da publicidad a la conversión en euros de las tarifas establecidas en la Orden de 30 de julio de 1988, por la que se establece el régimen de tarifas por servicios portuarios prestados por las Autoridades Portuarias ${ }^{6}$, al especificar los ámbitos de actividad de las Autoridades Portuarias en la prestaciones de los servicios portuarios, y deseable es que el Ente Público Puertos del Estado controle la sujeción a ley de las desafectaciones, como consecuencia de las nuevas infraestructuras portuarias - en construcción con generosas aportaciones de Fondos Comunitarios Europeos-y garantice el retorno al uso público ciudadano de las superficies portuarias innecesarias para las actividades portuarias.

La continuidad del cantil de los viejos muelles, desafectados de los usos portuarios, con los paseos marítimos o con las playas, acantilados o escolleras colindantes, es la premisa con la que opera la Ley de Costas, cuyo artículo 2, b) dispone como fin de la actuación administrativas en las costas:

«Garantizar el uso público del mar, de su ribera y del resto del dominio público marítimo-terrestre, sin más excepciones que las derivadas de razones de interés público debidamente justificadas».

El mandato legal transcrito tiene cadente secuencia en el punto c) del mismo precepto, al predeterminar los principios que marcan el operar de

${ }^{6}$ Boletín Oficial del Estado 28 de febrero de 2002. 
la actuación administrativa y, por ello, con vínculo para todas las Administraciones en la tramitación de sus procedimientos administrativos:

«Regular la utilización de estos bienes en términos acordes con su naturaleza, sus fines y con el respeto al paisaje, al medio ambiente y al patrimonio histórico».

No obstante, si en marcado contraste con la claridad de la Ley de Puertos y de la Ley de Costas, y de la coherente interrelación de sus preceptos, sus enunciados y sus procedimientos, fueren menoscabados por Alcaldes, Directores de Costas del Ministerio de Medio Ambiente, Delegados de Medio Ambiente autonómicos o Consejerías de Obras Públicas autonómicas, los valores y los procedimientos de la Ley de Costas y de la Ley de Puertos tienen el valioso referente de la voluntad ciudadana de hacer cumplir la Ley y, con ello, controlar jurídicamente y ajustar a Derecho la desviación o la incuria municipal, sin perjuicio de las actuaciones de control jurídico que propicien las acciones o inacciones de las Autoridades portuarias.

El ejercicio de la acción popular, reconocida por el artículo 109 de la Ley de Costas, es un incuestionable punto de atención jurídica activado por la desviación de las autoridades municipales por la vía de hecho.

La acción de sustitución ciudadana de la inactividad municipal, expresada en su dejación de competencia para incorporar al uso público municipal patrimonios que las Leyes de Costas y de Puertos entregan al uso ciudadano, es el recurso jurídico, propiciado por el artículo 68 de la Ley Básica de Régimen Local de 1985, con la finalidad de reivindicar la incorporación al uso público local de los viejos muelles que han dejado de estar al servicio de los usos portuarios. 